\title{
Correction to "Kinetics of Cyclophosphamide Metabolism in Humans, Dogs, Cats, and Mice and Relationship to Cytotoxic Activity and Pharmacokinetics"
}

\begin{abstract}
In the above article [Ramirez DA, Collins KP, Aradi AE, Conger KA, and Gustafson DL (2019) Drug Metab Dispos 47(3): 257-268; DOI: https://doi.org/10.1124/dmd.118.083766], the following funding information was omitted from the article:

This work was supported by the Pharmacology Shared Resource for the University of Colorado Cancer Center, which is funded by the National Institutes of Health National Cancer Institute [Grant P30 CA046934].

The HTML and PDF versions of the article have been corrected to include this information. The authors regret the omission of this information and any inconvenience it may have caused.
\end{abstract}

